\title{
Neonatal Hearing Loss: Outcomes of Universal Newborn Hearing Screening in a Tertiary Hospital Center
}

\author{
Gama R*, Alves S, Ribeiro L, Domingues B, Castro F, Silva J, Sousa A and Condé A \\ Department of Otorhinolaryngology, Head and Neck Surgery, Vila Nova de Gaia/Espinho Hospital Center, Portugal
}

Submission: November 08, 2019; Published: November 27, 2019

*Corresponding author: Gama R, Department of Otorhinolaryngology, Head and Neck Surgery, Vila Nova de Gaia/Espinho Hospital Center, Porto, Portugal

Abstract

Objective: To analyze the outcomes of the neonatal hearing screening in a cohort of children referred to the otolaryngology department of a tertiary hospital center and to make a literature review about the risk factors for hearing loss.

Methods: 5-year retrospective record review of 600 infants who did not pass newborn hearing screening and/or had one or more risk factors for hearing loss, who were referred for further evaluation in the Department of Otolaryngology of a Portuguese tertiary hospital, from September 2012 to December 2017.

Results: From the 600 newborns, hearing loss was detected in 36 infants (6\%), which means that the prevalence of hearing loss was 3.4 newborns per 1000 births. The most common risk factors were the use of ototoxic drugs, familial hearing loss, preterm birth, very low birth weight and low Apgar score. In the children with risk factors for hearing loss, hearing impairment was verified in only $2.43 \%$. On the other hand, from the 67 children without risk factors for hearing loss that did not pass the initial hearing screening tests, $34.3 \%$ were diagnosed with hearing impairment $(\mathrm{p}<0.05)$.

Conclusion: The most common risk factors were ototoxic medications, preterm birth, familial hearing loss, very low birth weight and low Apgar scores. The high incidence of sensorineural hearing loss in the absence of any known risk factor demonstrates the need to screen all the neonates.

Keywords: Newborn; Neonatal screening; Risk factor; Sensorineural hearing loss

\section{Introduction}

Hearing loss or hearing impairment is one of the most common congenital disorders, with an estimated prevalence of 0.5 to 5 infants per 1000 births [1-4]. The ability to hear during the early years of life is critical for the development of speech, language, and cognition; so even a mild and unilateral hearing loss in children can result in poor language, poor educational outcomes or even lead to a child being incorrectly labeled as having a behavior problem [5,6]. The only way to identify children with hearing impairment at such early time is by neonatal hearing screening. In the beginning of the program implementation period, only infants considered high-risk register (HRR) were contemplated. But it was not enough, given that as many as $50 \%$ of infants born with hearing loss have no known risk factors [7].

So today, a universal screening program is being implemented in all neonates. In Portugal, the first recommendations were done in 2005, by a multidisciplinary group named GRISI (Grupo de Rastreio e Intervenção da Surdez Infantil) [8], taking into account the principles and guidelines for interventional program issued by the Joint Committee on Infant Hearing (JCIH) [9]. All screening programs should rely on three mainstays: that all infants should have their hearing screening before their first month of age; for infants who do not pass the screening, diagnostic audiological evaluation should occur before 3 months of age; and infants with a confirmed hearing loss should be enrolled in an early intervention program before 6 months of age, to facilitate age appropriate development of language and social skills. The aim of this study was to determine the outcomes of the hearing screening program in our hospital and to characterize the association between the risk factors and hearing impairment, as well as to determine the prevalence of hearing loss in the group of children without risk factors.

\section{Materials and Methods}

It is a retrospective study, conducted in the Department of Otolaryngology and Head and Neck Surgery from a tertiary Hospital Center, during a 5-year-period (from September 2012 till January 2017). The data obtained from each child was maintained 
in two to six register (main register and follow-up registers). The data was analyzed accordingly to identify the most prevalent cause for the hearing loss among these infants. In this period, a total of 10.464 children were born in our hospital, which covers the geographic area of the county of Vila Nova de Gaia. All the infants born in the mentioned period were submitted to hearing screening tests. The selected population for the study included the newborns referred to ENT Department of our hospital, that is, who initially passed the hearing screening tests but were identified to have one or more risk factors for hearing loss and those who failed the initial hearing screening tests. Data were extracted regarding newborn hearing screening from a database in our department and from the records in children's clinical files.

According to the screening protocol, all newborns were screened in the maternity center during the first 48 hours of life using transient evoked optoacoustic emissions (TEOAEs). "Pass" means ear passed the test and "Refer" means ear failed the test. "Refer" result requires another evaluation at the maternity center, generally during the second week of life. Then a persistent "Refer" outcome requires referral for further evaluation in the Otolaryngology Department of our hospital center. That means that we evaluated all the newborns who had a persistent "Refer" outcome and all those who had at least one risk factor for hearing loss, regardless of the neonatal screening outcome. A complete otolaryngologic evaluation was performed in every referred neonate, as well as auditory brainstem response audiometry (ABR). Whenever necessary, a CT (computed tomography)-scan was performed, usually to characterize anatomic anomalies of the middle ear in syndromic children. Sensorineural hearing impairment was considered when ABR results showed high electrophysiological threshold (above 40dB).

The analyzed risk factors were the following: premature birth ( $<37$ weeks), very low birth weight $(<1500 \mathrm{~g})$, low Apgar score (0-4 at $1 \mathrm{~min}$ and $0-6$ at $5 \mathrm{~min})$, exposure to potentially ototoxic medications, severe hyperbilirubinemia that required exchange transfusion, prolonged assisted ventilation ( $\geq 5$ days), craniofacial anomalies, family history indicating hearing loss, postnatal infection, in utero infection (TORCH), and stigmata or diagnosed syndrome associated with hearing loss. The statistical analysis was performed using SPSS statistics version 25.0. A significance level of 0,05 was applied.

\section{Results}

A total of 600 infants were examined. Among these, 53.3\% were males and $46.7 \%$ were females. The mean gestational age was of $36 \pm 3.2$ weeks and the mean birth weight was $3200 \pm 431.2 \mathrm{~g}$.

\section{Hearing Impairment}

Within a total 10.464 born neonates, the prevalence of hearing impairment in the referred population was 3.4 per 1000 births, with almost $94 \%$ being normal hearers. No significant association was verified between the gender of the neonates and the prevalence of hearing loss. About $89 \%(n=533)$ of the newborns had at least one risk factor, while only $11 \%(n=67)$ had no risk factors for hearing loss.

\section{Neonates with Risk Factors}

The most frequent risk factor was the use of ototoxic medications $(n=243 ; 45.6 \%)$, followed by preterm birth $(n=155$; $29.1 \%)$; familial hearing loss ( $n=148 ; 27.8 \%)$, very low birth weight ( $n=114 ; 21.4 \%)$; and low Apgar scores ( $n=67 ; 12.6 \%)$ (Figure 1). The most common concomitant risk factors were preterm birth, very low birth weight and the use of ototoxic medications, verified in 143 children in the risk factor group. The most common potentially ototoxic drug was gentamicin. In this group of children, hearing impairment was verified in $2.43 \%(n=13)$. We verified an association between craniofacial anomalies and later development of conductive type of hearing loss (predominantly caused by effusion otitis), in most cases resolved with trans tympanic ventilation tube. This was one of the strongest associations found in our population ( $\mathrm{p}=0.08)$. Cleft palate was the most common found isolated craniofacial anomaly.

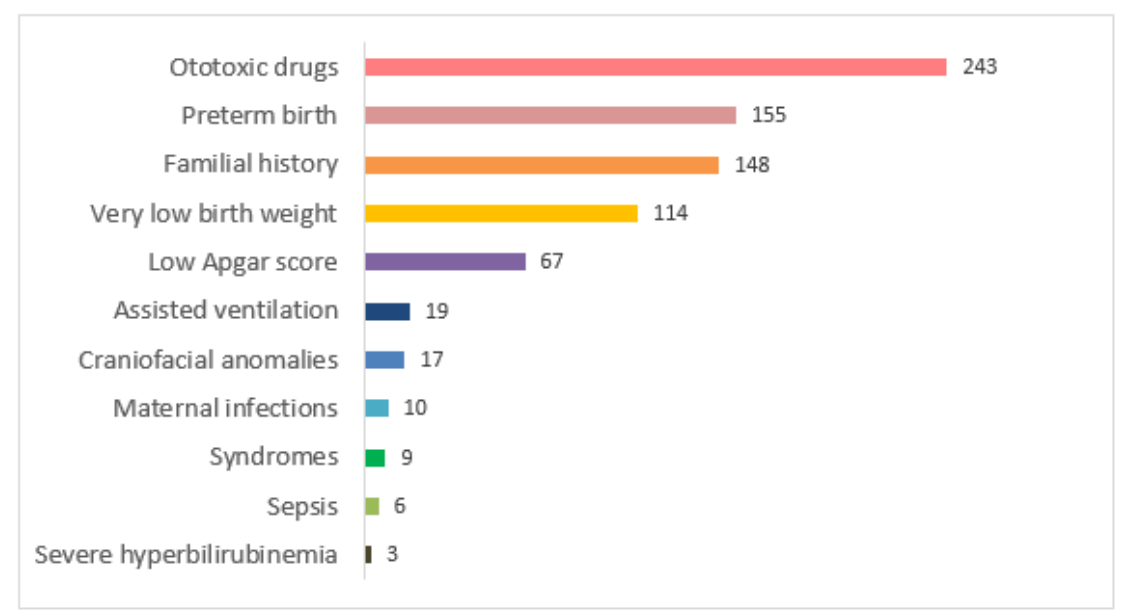

Figure 1: Prevalence of risk factors for hearing loss in the studied newborn population. 


\section{Neonates without Risk Factor}

A total of 67 children without risk factors for hearing loss that did not pass the initial hearing screening tests were referred to our department for further evaluation. In this group, it was verified a total of $34.3 \%(n=23)$ of newborns with hearing impairment; $65.7 \%(n=44)$ of the referred neonates without risk factors did not show any degree of hearing loss.

\section{Discussion}

The total prevalence of hearing loss in this study was 3.4 infants per 1000 newborns, a value in accordance with the general estimated values described in the literature $[1,3,4]$. In our population, the most frequent risk factor was the use of ototoxic medications. Ototoxic drugs, specifically aminoglycosides, can be administered to newborns. Preterm birth is a known risk factor for neonatal early-Oncet septicemia, mostly caused by group-B Streptococcus and Escherichia coli [10]. The most recommended therapy for the infections caused by these microorganisms is the association between a beta-lactamic and an aminoglycoside (generally Gentamicin) [10-12]; The potential ototoxicity of aminoglycosides may be one of the reasons that justify the rate of hearing impairment in our preterm newborn population.

However, the association between aminoglycoside administration and hearing loss is inconsistent among studies; most studies reported no significant association with treatment duration, total dose, peak or even serum concentrations [1315], whereas others reported a significant and evidence-based ototoxicity of aminoglycosides [13,14,16,17], particularly on high frequency hearing [17-20]. In some individuals, genetic predisposition is associated with aminoglycoside-induced sensorineural hearing loss, making them particularly vulnerable to this drug toxicity [21]. Other potentially ototoxic drugs described in the literature are loop diuretics; the association between loop diuretics administered to neonates and hearing loss is also inconsistent. However, their use or overuse in combination with other treatments (e.g., aminoglycosides) appears to be associated with sensorineural hearing loss [17,21-23] which needs further investigation.

Other frequent risk factors included specific conditions of the neonate, as gestational age $<37$ weeks, birth weight $<1500 \mathrm{~g}$ and Apgar score of 0-4 at $1 \mathrm{~min}$ and/or 0-6 at 5min. Studies analyzing low birth weight used different classifications of birth weight, such as low, very low, or extremely low birth weight. Most studies do not provide evidence of a direct association between the neonatal hearing loss and low birth weight, although the prevalence of sensorineural hearing loss is higher in low birth-weight neonates $[24,25]$. This can be explained by the factors commonly related to low birth weight that may have impacted hearing, such as assisted ventilation, ototoxic drug administration, or hyperbilirubinemia $[18,26]$.

Most studies failed to account for these confounding variables in multivariable analysis. Therefore, this association is still not completely clarified. Another specific indicator of neonates is the Apgar score, which is used as an indicator of birth asphyxia. Studies analyzing the association between Apgar score with hearing loss were difficult to compare: the timing of the Apgar score and cutoff for birth asphyxia varied considerably. In some studies, a low Apgar score was associated with sensorineural hearing loss or abnormal hearing results, while in others this association was not verified $[19,20,27]$. Therefore, further studies are required to clarify the duration of asphyxia, permanent characteristics of hearing deficits related to the Apgar score and birth asphyxia, and role of prematurity, which appears to be a confounding factor $[19,20,27,28]$.

We verified that $65.7 \%$ of the referred neonates without risk factors for hearing loss did not show any degree of hearing loss in the following auditory assessment tests; this means that there is a high rate of false-positive results concerning the initial automatic Otoe mission screening tests performed in the maternity center [29-33]. The hypotheses to justify this result are being investigated and may be related to the presence of vernix caseosa in the external auditory canal, lack of calibration of the equipment, poor probe tip placement or poor seal. Other possible related factors are being proposed in the literature, as mother's smoking habits and drug abuse; a recent study concluded that these two factors affect the outcome of OAE results (biasing towards a false-positive), such that if the mother is a smoker and/ or drug user, her newborn has a higher chance of failing the OAE hearing screening test due to a conductive component [34]. These possible risk factors lack, however, strong evidence and still need to be investigated.

On the other hand, the high prevalence of sensorineural hearing impairment verified in children without risk factors for hearing loss confirms the need to screen every single newborn. This result was verified in several previous studies $[1,4,5,35]$ being the main motivation for the universality of the screening programs.

\section{Limitations}

As limitations of our study we can list the following: those inherent in a retrospective study, as the selection and information bias; all our data is reliant upon provider-reported input; the presence of cases lost to follow up, so the prevalence of hearing loss in the studied population is probably underestimated.

\section{Conclusion}

The total prevalence of hearing loss in our newborn population was 3.4 per 1000 births. The most common risk factors were ototoxic medications, preterm birth, familial hearing loss, very low birth weight and low Apgar scores. We concluded that the high percentage of children with sensorineural hearing loss in the absence of any known risk factor demonstrates the need to screen all neonates. Further studies are warranted to clarify the role of each risk factor in the hearing loss physiopathology. 


\section{Global Journal of Otolaryngology}

\section{References}

1. TP N (2015) Neonatal hearing screening: What we have achieved and what needs to be improved. Int J Pediatr Otorhinolaryngol 79(5): 635637

2. Berry SA (2015) Newborn Screening. Clin Perinatol 8(15): 0095-510.

3. Watkin P, Baldwin M (2012) The longitudinal follow up of a universal neonatal hearing screen : The implications for confi rming deafness in childhood. Int J Audiol 5: 519-528.

4. Szyfter W, Wro MJ (2014) The risk factor profile of children covered by the Polish universal neonatal hearing screening program and its impact on hearing loss incidence. Int J Pediatr Otorhinolaryngol 78 209-213.

5. Saki N, Bayat A, Hoseinabadi R, Nikakhlagh S, Karimi M (2017) Universal newborn hearing screening in southwestern Iran. Int J Pediatr Otorhinolaryngol 97: 89-92.

6. Appelbaum EN, Howell JB, Chapman D, Pandya A, Dodson KM (2018) Analysis of risk factors associated with unilateral hearing loss in children who initially passed newborn hearing screening. Int J Pediatr Otorhinolaryngol 106: 100-104.

7. Downs MP1 Y-IC (1999) The efficacy of early identification and intervention for children with hearing impairment. Pediatr Clin North Am 46(1): 79-87.

8. Pediatria SPDE (2007) Recomendações para o Rastreio Auditivo Neonatal Universal (RANU) Grupo de Rastreio e Intervenção da Surdez Infantil - GRISI 209-214

9. Joint Committee on Infant Hearing (2007) Year 2007 Position Statement: Principles and Guidelines for Early Hearing Detection and Intervention. Pediatrics 120: 898-921.

10. Crivaro V, Bagattini M, Salza MF E al (2007) Risk factors for extendedspectrum betalactamase-producing Serratia marcescens and Klebsiella pneumoniae acquisition in a neonatal intensive care unit. J Hosp Infect 67: 135-141.

11. Rao SC, Ahmed M HR (2006) One dose per day compared to multiple doses per day of gentamicin for treatment of suspected or proven sepsis in neonates. Cochrane Database Syst Rev 11.

12. Kaufman D, Fairchild KD (2004) Clinical Microbiology of Bacterial and Fungal Sepsis in Very-Low-Birth-Weight Infants. Clin Microbiol Rev 17(3): 638-680.

13. De Hoog M, van Zanten BA, Hop WC, Overbosch E, Weisglas Kuperus N V, et al. (2003) Newborn hearing screening: tobramycin and vancomycin notrisk factors for hearing loss. J Pediatr 142: 41-46.

14. De Hoog M, van Zanten GA, Hoeve LJ, Blom AM van den AJ (2002) A pilot case control follow-up study on hearing in children treated with tobramycin in the newborn period. Int J Pediatr Otorhinolaryngol 65: 225-232.

15. Setiabudy R, Suwento R, Rundjan L, Yasin FH, Louisa M, et al. (2013) Lack of a relationship between the serum concentration of aminoglycosides and ototoxicity in neonates. Int J Clin Pharmacol Ther 51: 401-6.

16. Kraft CT, Malhotra S, Boerst A TM (2014) Risk indicators for congenita and delayed-onset hearing loss. Otol Neurotol 35: 1839-1843.

17. Naeimi M, Maamouri G, Boskabadi H, Golparvar S, Taleh M, et al (2009) Assessment of aminoglycoside-induced hearing impairment in hospitalized neonates by TEOAE. Indian J Otolaryngol Head Neck Surg 61: $256-261$.
18. R Cristobal JSO (2008) Hearing loss in children with very low birth weight: current review of epidemiology and pathophysiology. Arch Dis Child Fetal Neonatal Ed 93: 462-468.

19. Jiang ZD WA (2006) Neonatal auditory function and depressed Apgar score: correlation of brainstem auditory response with Apgar score. Acta Paediatr 1556-60.

20. E. B (1997) Perinatal asphyxia, hypoxia, ischemia and hearing loss Scand Audiol 26: 77-91.

21. Estivill X, Govea N, Barcelo E, Badenas C, Romero E, Moral L et al. (1998) Familial progressive sensorineural deafness is mainly due to the mtDNA A1555G mutation and is enhanced by treatment of aminoglycosides. Am J Hum Genet 62: 27-35.

22. Brown DR, Watchko JF SD (1991) Neonatal sensorineural hearing loss associated with furosemide: a case-control study. Dev Med Child Neurol 33: 816-23.

23. Vella Brincat JW, Begg EJ, Robertshawe BJ, Lynn AM, Borrie TL DB (2011) Are gentamicin and/or vancomycin associated with ototoxicity in the neonate? A retrospective audit. Neonatology 100: 186-193.

24. Doyle LW, Keir E, Kitchen WH, Ford GW, Rickards AL KE (1992) Audiologic assessment of extremely low birth weight infants: a preliminary report. Pediatrics 90: 744-749.

25. Mart CF, Garc P, Ochoa l JM (2012) Hearing Loss , Auditory Neuropathy, and Neurological Co-morbidity in Children with Birthweight! $750 \mathrm{~g}$ Arch Med Res 43: 457-63.

26. Soleimani F, Zaheri F, Abdi F (2014) Long-Term Neurodevelopmental Outcomes After Preterm Birth. Iran Red Crescent Med J 16(6).

27. Kvestad E, Lie KK, Eskild A EB (2014) Sensorineural hearing loss in children: the association with Apgar score. A registry-based study of 392,371 children in Norway. Int J Pediatr Otorhinolaryngol 78: 19401944.

28. Hille ET, van Straaten HI VP (2007) Prevalence and independent risk factors for hearing loss in NICU infants. Acta Paediatr 96: 1155-8.

29. Zakzouk SM BS (1996) Prevalence of Severe to Profound Sensorineural Hearing Loss in Children Having Family Members With. Ann Otol Rhinol Laryngol 105: 882-886.

30. Bener A, Eihakeem AAM, Abdulhadi K (2005) Is there any association between consanguinity and hearing loss. Int J Pediatr Otorhinolaryngol 69: 327-333.

31. Grundfast KM, Siparsky N CD (2000) Genetics and Molecular Biology of Deafness. Update. Otolaryngol Clin North Am 33(6): 1367-1394.

32. Pickett BP, Ahlstrom K (1999) Clinical Evaluation of the HearingImpaired Infant. Otolaryngol Clin North Am 32: 1019-1035.

33. Driscoll C, Beswick R, Doherty E, Silva RD, Cross A (2015) The validity of family history as a risk factor in pediatric hearing loss. Int J Pediatr Otorhinolaryngol 79(5): 654-659.

34. Schwarz Y, Kaufman G N, Daniel SJ (2017) Newborn hearing screening failure and maternal factors during pregnancy. Int J Pediatr 103: 65-70.

35. Wroblewska seniuk K, Dabrowski P, Greczka G, Glowacka A, Mazela J (2018) Sensorineural and conductive hearing loss in infants diagnosed in the program of universal newborn hearing screening. Int J Pediatr Otorhinolaryngol 105: 181-186. 
(C) Commons Attribution 4.0 License (CC) DOI: 10.19080/GJO.2019.21.556058
Your next submission with Juniper Publishers will reach you the below assets

- Quality Editorial service

- Swift Peer Review

- Reprints availability

- E-prints Service

- Manuscript Podcast for convenient understanding

- Global attainment for your research

- Manuscript accessibility in different formats

( Pdf, E-pub, Full Text, Audio)

- Unceasing customer service

Track the below URL for one-step submission https://juniperpublishers.com/online-submission.php 